This article was downloaded by:

On: 3 February 2010

Access details: Access Details: Free Access

Publisher Routledge

Informa Ltd Registered in England and Wales Registered Number: 1072954 Registered office: Mortimer House, 3741 Mortimer Street, London W1T 3JH, UK

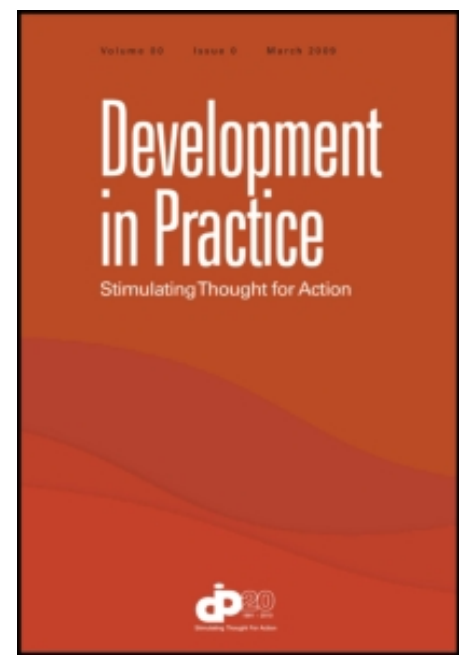

\title{
Development in Practice
}

Publication details, including instructions for authors and subscription information:

http://www.informaworld.com/smpp/title content=t713412875

\section{Relationships, learning, and trust: lessons from the SNV-RECOFTC partnership}

Sango Mahanty a; Yurdi Yasmi; John Guernier; Rob Ukkerman; Lucia Nass

${ }^{a}$ Resource Management in the Asia Pacific Program, Research School of Pacific and Asian Studies,

ANU College of Asia and the Pacific, Australian National University, Canberra, Australia

To cite this Article Mahanty, Sango, Yasmi, Yurdi, Guernier, John, Ukkerman, Rob and Nass, Lucia(2009) 'Relationships, learning, and trust: lessons from the SNV-RECOFTC partnership', Development in Practice, 19: 7, 859 - 872

To link to this Article: DOI: $10.1080 / 09614520903122212$

URL: http://dx.doi.org/10.1080/09614520903122212

PLEASE SCROLL DOWN FOR ARTICLE

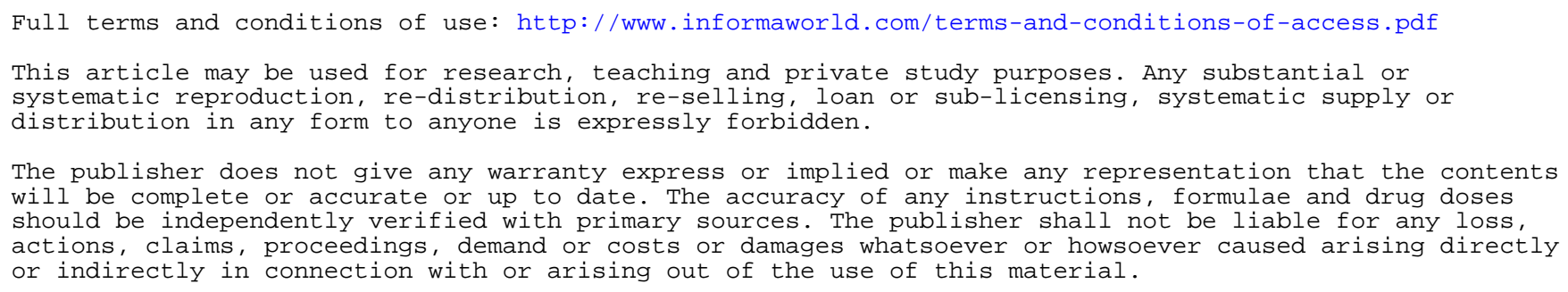




\title{
Relationships, learning, and trust: lessons from the SNV-RECOFTC partnership
}

\author{
Sango Mahanty, Yurdi Yasmi, John Guernier, \\ Rob Ukkerman, and Lucia Nass
}

The term 'partnership' has become a watch-word for development organisations that aim to mobilise the resources and collaboration needed to achieve long-term goals such as poverty reduction and sustainable resource management. Achieving effective collaboration in practice, however, can be challenging. This article adds to recent discussions on what makes effective partnerships, offering lessons from an on-going partnership between RECOFTC (Regional Community Forestry Training Center for Asia and the Pacific) and SNV (Netherlands Development Organisation). Key findings include the observation that the role of individuals in maintaining partnerships often goes unrecognised and needs to be supported in appropriate ways; clearly defined and focused areas of collaboration are essential; a formal basis for the partnership needs to be backed with strong informal communication and collaboration processes; and, while partners bring distinctive knowledge and networks to a partnership, some degree of evenness in the scale and type of resources committed to the partnership is important.

Key Words: Civil Society; Environment; Methods; East Asia; South Asia

\section{Introduction}

Over the course of two years, the Regional Community Forestry Training Center for Asia and the Pacific (RECOFTC) and SNV Netherlands Development Organisation (SNV) implemented a formal partnership agreement based on a joint agenda of poverty reduction and sustainable forest management. Such partnerships are becoming the lifeblood of development organisations looking for innovative ways to mobilise resources for maximum development impact. Previous research has shown, however, that there are challenges in building trustful, effective, and equitable relationships between partners, given differences in organisational skills, cultures, power, agendas, and assets (Fowler 1998; Brinkerhoff 2002; Brinkerhoff and Brinkerhoff 2004; Ylitalo et al. 2005). This article contributes to discussions about how partnerships can address these challenges to achieve more effective collaboration. 
The definitions of partnership are as numerous as the forms that they take. Pickard (2007) suggests that partnerships between Northern and Southern organisations might be based on equal standing but differentiated responsibilities between partners. Partnerships between state and civil society or community bodies might take the form of co-operative relationships to fulfil a specific policy function (Marra 2004). The SNV-RECOFTC partnership differs from these in some respects, as the partnership has been open-ended rather than project-bound, and arose between two international organisations that, in theory at least, entered the union as equals. Brinkerhoff's (2002) definition is particularly relevant to such a partnership:

[A] dynamic relationship among diverse actors based on mutually agreed objectives, pursued through a shared understanding of the most rational division of labour based on the respective comparative advantages of each partner. Partnership encompasses mutual influence, with a careful balance between synergy and respective autonomy, which incorporates mutual respect, equal participation in decision-making, mutual accountability and transparency. (Brinkerhoff 2002: 216)

Maintaining a union between equals is not straightforward, given a range of intra- and interorganisational factors that can come into play (Fowler 1998; Lister 2000; Brinkerhoff 2002). Brinkerhoff synthesises these into three central pillars that shape overall partnership performance: the conditions under which partnerships form, the functioning of the partnership, and partnership outcomes. In terms of each of these pillars, she identifies the critical factors that together form a framework to assess the performance of partnerships (see Table 1).

This framework resonates with issues emerging from other partnership research, such as: the importance of strong and trustful personal relationships (Lister 2000; Vincent and Byrne 2006); the need to address power differentials for a partnership to be 'authentic' (Lister 2000; Fowler 1998; Hoksbergen 2005); the importance of learning within the partnership (Vincent and Byrne 2006); and the need for compatible organisational conditions as well as equal standing (Fowler 1998). These factors are found within Brinkerhoff's framework, with the exception of an explicit focus on the intra-organisational conditions discussed by Fowler (1998), which is taken up to some extent in our discussion of organisational 'readiness' for partnerships.

Brinkerhoff's framework provides a relevant synthesis of existing partnership-related research, but little is known about its applicability in assessing partnerships for natural-resource management (NRM). In applying the framework, this article therefore aims not only to contribute to the understanding of key factors affecting partnerships, but also to explore the applicability of this framework for NRM-related partnerships, which are tackling complex, long-term issues which require action at multiple levels.

Brinkerhoff's framework is used here to analyse the conditions, processes, and outcomes in the SNV-RECOFTC partnership. The discussion that follows does not address all the factors identified in her framework, but focuses instead on those points where a substantive lesson has emerged in the RECOFTC-SNV case (shown in bold in Table 1). The article draws on the discussions and critical reflections of the authors, as well as an evaluation (Nass 2007) and Master's research project (Donnelly 2007) which independently examined the partnership.

First we look briefly at the partnership, how it developed, what it aimed to achieve and with what resources. We then examine critical issues related to partnership conditions, processes, and outcomes in the SNV-RECOFTC partnership. Finally, we reflect on lessons from the SNV-RECOFTC experience, in terms of how development organisations might strengthen their own partnership-development processes, with particular lessons for developing effective NRM-related partnerships. 
Table 1: Key factors in assessing partnership performance

\begin{tabular}{|c|c|}
\hline $\begin{array}{l}\text { 1. Partnership conditions } \\
\text { and formation }\end{array}$ & $\begin{array}{l}\text { a. partner compatibility: understanding of each other's mission, } \\
\text { operating cultures, constituencies, core values, and mechanisms to } \\
\text { address any incompatibilities, historical relationships } \\
\text { b. clear partnership goals (reviewed regularly, common vision, } \\
\text { mutually determined and agreed) } \\
\text { c. ability to share power } \\
\text { d. existence of partnership champions } \\
\text { e. confidence in organisational procedures and degree of formality } \\
\text { f. senior management support (participation, allocation of resources) } \\
\text { g. willingness to meet partnership needs } \\
\text { h. ability to perform agreed actions, given external factors and capacity }\end{array}$ \\
\hline $\begin{array}{l}\text { 2. Partnership } \\
\text { functioning }\end{array}$ & $\begin{array}{l}\text { Mutuality and equality in terms of: } \\
\text { a. mutual trust in character and competency } \\
\text { b. flexibility } \\
\text { c. balanced exchange in level and nature of resources } \\
\text { d. reciprocal accountability through regular reporting, access to } \\
\text { performance information, financial controls, joint design of } \\
\text { evaluations/assessments } \\
\text { e. decision-making processes (satisfaction, joint determination of } \\
\text { activities and procedures, process for determining division of labour } \\
\text { and risk/reward balance) } \\
\text { f. transparency through established channels for information sharing } \\
\text { and dialogue (beyond formal agreement) } \\
\text { g. presence/absence of dominating partners } \\
\text { h. partner representation and participation in partnership activities, } \\
\text { planning and review meetings, and rules governing representation of the } \\
\text { i. mutuality in planning meetings, understanding of unique strengths of } \\
\text { each partner, shared understanding of partner drivers } \\
\text { j. evenness and perceived fairness of benefit distribution } \\
\text { k. fulfilling roles and responsibilities to mutual satisfaction } \\
\text { 1. conflict (degree, frequency, extent and management) } \\
\text { Identities of partners are maintained and grow through partnership (mission } \\
\text { and methods for assessing its attainment, constituents, underlying values, } \\
\text { culture). }\end{array}$ \\
\hline 3. Partnership outcomes & $\begin{array}{l}\text { a. value added to partners' outcomes in qualitative and quantitative } \\
\text { terms } \\
\text { b. individual partners enhance own capacity and influence and meet } \\
\text { their objectives } \\
\text { c. synergistic outcomes and multiplier effects } \\
\text { d. linkages with other programmes/actors } \\
\text { e. identification of critical factors influencing partnership's success } \\
\text { f. continuous monitoring and strategic management } \\
\text { g. the partnership gains an identity (culture, values, mission) and } \\
\text { recognition based on its comparative advantage }\end{array}$ \\
\hline
\end{tabular}

(Adapted from Brinkerhoff 2002. The bold text identifies factors that have been significant in the RECOFTC-SNV relationship; these are referred to through the article.) 


\section{Overview of the SNV-RECOFTC partnership}

SNV and RECOFTC are both well-established international organisations with an interest in sustainable natural-resource management and participatory development (see Box 1). Informal interaction over several years between individual staff working with SNV and RECOFTC was the starting point for the formal partnership. In addition, both organisations had an expressed interest in partnership development as a basis for programme innovation and up-scaling of country-specific experiences (in the case of SNV) and to multiply resources and extend impact (in the case of RECOFTC). The Letter of Agreement (LoA) that signified the shift to a formal partnership was signed by senior managers in November 2005.

\section{Box 1. Introducing RECOFTC and SNV}

The Regional Community Forestry Training Center for Asia and the Pacific is an international not-for-profit organisation based in Bangkok which supports community forestry and community-based natural-resource management. RECOFTC receives core funding from the Swedish International Development Co-operation Agency (SIDA), the Swiss Agency for Development and Cooperation (SDC), and the Norwegian Ministry of Foreign Affairs. Through strategic partnerships and collaboration with government and non-government institutions, programmes, projects, and networks, RECOFTC aims to enhance capacity at all levels and promote constructive multi-stakeholder dialogues and interactions, to ensure equitable and sustainable management of forest resources. (See www.recoftc.org.)

SNV Netherlands Development Organisation is a Netherlands-based international NGO which delivers capacity-building advisory services to more than 2000 clients in 33 countries in Africa, Asia, Latin America, and the Balkans. In Asia, SNV provides these services to government, non-government, and private-sector organisations in Nepal, Vietnam, Bhutan, Laos, Cambodia, and Bangladesh, as well as to a number of regional organisations and networks. Its 150 advisers in Asia work with local actors, primarily those who operate at national and meso levels in strengthening their capacity to effectively reduce poverty reduction and improve governance. SNV aims to achieve development results in two areas: (1) reducing extreme poverty by increasing production, employment, and equitable income opportunities via its work in Smallholder Cash Crops, Pro-poor Sustainable Tourism, and Forest Products; (2) improving the access, coverage, and quality of basic services via its work in Water, Sanitation \& Hygiene, and Renewable Energy. (See www.snvworld.org)

The LoA set out a joint agenda for sustainable forest management in Asia (Bhutan, Cambodia, Laos, Nepal, and Vietnam), combining the community forestry, regional capacity, and training expertise of RECOFTC with the advisory services, capacity-development services, and sub- and national linkage of SNV. An appendix to the LoA set out the specific annual programme of work.

The partnership so far has involved the implementation of two work programmes with associated budgets negotiated and agreed annually. Key fields of co-operation are outlined in Box 2, although it is important to note that specific activities were identified under these broad fields. These activities are not described in detail here, but specific examples are referred to where relevant. Some activities were identified during annual plans, and others were added as new opportunities emerged. 


\section{Box 2. Fields of co-operation outlined in the partnership agreement}

Advisory services: making use of each organisation's services to meet a demand from other partners and clients who may not have the capacity to cover the costs of such services.

Innovation: developing new services and approaches to collaborative forest management, for example: capacity building to improve local forest governance, activities to strengthen the equity of benefit and cost sharing in community forestry, and judicious uptake of new opportunities such as payments for environmental services.

Staff exchange: exchanging staff for purposes of programme development, training, or joint activities at country and regional levels.

Knowledge and network sharing: between partners (networks, information on best practices, current strategies and activities in the region, and opportunities to participate in each other's meetings and workshops on topics of mutual interest) and with wider audiences (joint publication and documentation of best practices).

Acquisition and funding: collaborating to seek and diversify funding resources.

In the first year, a total budget of US\$23,000 was allocated by SNV, but only 20 per cent was spent, in part due to the time taken in starting up partnership activities. In the second year, a total budget of US\$ 189,000 was allocated and fully used (53 per cent by SNV and 47 per cent by RECOFTC, although some of the RECOFTC funds in this equation were actually for activities budgeted outside the partnership, meaning that the SNV funding was actually a higher proportion than indicated). Although both organisations committed resources to the partnership, the type of resource committed by SNV tended to be financial, with some staff time spent on specific activities, while the RECOFTC commitment was most often in the form of staff time. RECOFTC also took responsibility for managing and reporting on the partnership budget and implementation. The implications of these different modes of contribution to the partnership and reporting arrangements are discussed below. In some respects this brought a donor-recipient flavour to the relationship of the kind discussed by Marra (2004), although the most highly valued collaborations involved a more even contribution from each partner (see Box 3).

\section{Strengths and weaknesses of the SNV-RECOFTC partnership}

\section{Partnership conditions and formation}

A level of compatibility in organisational mission and culture is needed for a partnership to emerge in the first place (Brinkerhoff 2002; Table 1, 1a). In addition, balanced partnerships are more likely to evolve when organisations have similar standing and mutually valued assets (Fowler 1998).

In the case of RECOFTC and SNV, these conditions were partly met. Each organisation enjoyed strong standing in Asia, as regional (RECOFTC) and national (SNV) players in NRM and community development. They also shared agendas in community-based forest management, capacity building, and poverty reduction. These shared agendas informed the objectives outlined in the LoA, of capacity building and contributing to poverty reduction in the region. The partnership was designed to up-scale national activities and knowledge, a perceived strength of SNV, to the regional level through RECOFTC's regional linkages. It was felt that this was where the partnership could add value to their other initiatives in the region and address the multiple levels required for effective and equitable forest governance. 
Table 2: Strengths and weaknesses in partnership conditions and formation

\begin{tabular}{|c|c|}
\hline Strengths & Weaknesses \\
\hline $\begin{array}{l}\text { Shared interest in partnership and compatibility of } \\
\text { organisational agendas and cultures }\end{array}$ & $\begin{array}{l}\text { Partnership objectives, outcomes, and } \\
\text { activities too broad in scope }\end{array}$ \\
\hline Champions to lead partnership development & $\begin{array}{l}\text { A broad base of support for the partnership } \\
\text { took time to develop }\end{array}$ \\
\hline \multicolumn{2}{|l|}{$\begin{array}{l}\text { Formal agreement that covered key issues and was } \\
\text { developed through a consultative process }\end{array}$} \\
\hline $\begin{array}{l}\text { Senior management role important in strategic planning } \\
\text { in the partnership }\end{array}$ & $\begin{array}{l}\text { Partnership 'champions' dissipated during } \\
\text { implementation phase }\end{array}$ \\
\hline $\begin{array}{l}\text { Formal commitment of financial and staff resources to } \\
\text { implement agreed activities }\end{array}$ & $\begin{array}{l}\text { Short-term planning horizon led to only } \\
\text { short-term activities }\end{array}$ \\
\hline
\end{tabular}

Articulating the objectives (Table 1, reference 1b) at this very broad level enabled the core interests of the two organisations to be recognised in a very wide range of collaborative activities. This breadth brought advantages and disadvantages (summarised in Table 2). While it meant that the partnership could engage various staff and programmes, rather than remaining within the remit of one or two champions in each organisation, on the downside the goals were not necessarily clear and focused, which led to a long list of activities (10 in the first year). Furthermore, although many were engaged in conceptualising the activities, their implementation did fall primarily to a few members of staff, which meant that many of the activities that were planned and budgeted for were not implemented in the first year. A clearer and more closely defined set of objectives and activities would have helped to refine collaborative activities to a core set that could be effectively implemented. In this sense, partnership condition 1.b was only partially met.

As observed in previous partnership research (Brinkerhoff 2002; Table 1, 1d), champions and leaders within the two organisations did play an important role in the emergence of this partnership, although their roles shifted over time. In the initial stages, the respective programme managers drove the partnership-development process and were focal points for its management. The engagement of programme managers was useful, because they had knowledge of implementation issues, while being connected to strategic decisions within their organisations. A disadvantage in relying strongly on such champions was that staff changes strongly affected the partnership and contributed to the slow start-up of partnership activities in its first year.

Over time, the involvement of senior managers from each organisation declined, which staff felt was appropriate during the implementation stage, because there had been no major problems apart from the slow start noted earlier. As the initial phase of the partnership came to a close, senior managers were again expected to take on a more substantial role in determining the future of the partnership, to ensure that it remained strategically aligned with organisational plans and programmes. Such 'champions', people with strategic roles in their respective organisations, are important in the early phases and at the review stage (Table 1, 1d and 1f).

Developed through a process of consultation within and between the two organisations, the LoA formally committed each organisation to collaborate over a two-year period. It outlined procedures for making decisions on and implementing the Agreement, review and monitoring processes, reporting, dispute resolution, disclosure of information about the partner, financial arrangements, and termination of the agreement. Defining roles, responsibilities, and operating procedures in this way, as noted in previous partnership research, helped to build confidence between the partner organisations and set out a clear modus operandi for the partnership (Brinkerhoff 2002; Donnelly 2007; Table 1, 1e). 
The commitment of financial resources and staff time by the two organisations was important, making it possible to implement activities and to see real outputs from the partnership in a relatively short period (Table $1,1 \mathrm{f})$. A limitation, however, was the short (one-year) duration of the planning and implementation cycle, which arose initially because of SNV's budgetary limitations. The annual planning process limited the potential to develop and implement longer-term activities, and weighed more in favour of short-term activities that could be implemented over a year. In addition, the lag time in initiating and implementing activities was not allowed for in planning, which meant that considerable funds remained unspent in the first year.

\section{Partnership functioning}

Trust between partners is a necessary basis for mutuality and joint action (Brinkerhoff 2002; Tonkiss and Passey 1999; Table 1, 2a). But what is trust, and how can it be fostered in a partnership? The Oxford English Dictionary explains trust as the ability to rely upon a quality or attribute of a partner, with the implication that each partner feels safe and secure in sharing information and resources, and in depending upon one another in various capacities. Honesty in dealings is another important facet of maintaining trust.

In the SNV-RECOFTC partnership, trust was built and maintained through a number of processes. At the organisational level, there was a degree of trust established through mutual knowledge of each other's work and reputation. Compatible organisational cultures also played a role, as a level of comfort is needed with transparency and openness for trust between organisations to develop and deepen over time.

First and foremost, however, trust was fostered through the relationships between individual members of staff. Given the culturally diverse nature of the organisations, particularly RECOFTC, opportunities for personal interaction were an important way to build mutual understanding. One staff member noted that the overall partnership included many nested partnerships around specific activities, which individual staff developed through close collaboration. The open communication and trust established in these nested partnerships strengthened the overall relationship between the two organisations, a point also observed in previous partnership research (Lister 2000). Trust was also strengthened through open and regular communication, for example meeting informally during country visits, and regular email and telephone conversations. As one staff member observed: partnerships only work if the individuals involved want to work together and have commitment (cited in Donnelly 2007: 16).

Many staff noted that the SNV-RECOFTC partnership was characterised by a high degree of flexibility in terms of the possibility to adapt work programmes to adjust activities or incorporate new activities (Table 1, 2b). Several adjustments of this kind occurred through agreement at meetings or by exchange of emails, although it did not extend to the flexibility to move funds between years. A recent evaluation states: 'SNV's flexible stance on the use of funds has contributed to the understanding by RECOFTC that SNV is a partner that understands process orientation and adaptability' (cited in Nass 2007: 18).

Flexibility enabled the partners to take advantage of opportunities to mobilise additional funds for activities through strategic alliances with other organisations. Activities were often added, adapted, or extended during this process. Several fruitful alliances were made with organisations outside the partnership, including the learning initiative on benefit sharing in community-based resource management (with WWF); an international conference on forest harvesting and poverty reduction (with FAO, ITTO, DGIS, and others); a workshop on payment for environmental services (with ICRAF, IIED, Winrock India, and others); and the Second Community Forestry Forum for senior regional policy makers (with FAO). 
A challenge posed by this degree of flexibility was the mushrooming of new activities under the agreement. A clear and focused set of objectives and outcomes articulated in the LoA would have helped to contain this trend. On balance, however, the level of flexibility possible in the partnership was valued by staff and, given the differential nature of resources invested by each partner (see below), helped to alleviate an imbalance in power that might otherwise have emerged.

Another important condition for effective partnerships, according to Brinkerhoff (2002), is a balanced contribution by partners to the partnership (Table 1, 2c). An imbalance in the contribution of finance by SNV versus staff time by RECOFTC was noted earlier, originating in the historical circumstances of each partner. At the outset, SNV had funding for 'innovation' activities, while RECOFTC at that time faced a shortfall in its core funding which was subsequently filled. RECOFTC had therefore agreed to take responsibility for managing the partnership funds for which it received a management fee, and took the lead in managing partnership activities and reporting on these. Because of the way in which arrangements evolved, the reporting arrangements and accountability for partnership implementation became uni-directional rather than joint (Table 1, 2d).

A negative aspect of this arrangement was the perception among a number of RECOFTC staff that much of the intellectual and staff-time contribution for partnership activities was coming from them, while SNV functioned as a donor. This perception was reinforced by the requirement that only RECOFTC prepared progress and financial reports on the partnership, regardless of the fact that a management fee had been agreed for this role (Box 3). There was also no clear system in place to track staff-time inputs in both organisations, which in the early phase of the partnership might have helped to create the opportunity to discuss issues arising from the different types of input being provided by each partner. Without a clearly visible balance, staff commitment to the partnership was at risk of eroding. At the same time, as Box 3 highlights, there were cases where staff from both organisations contributed substantial time and intellectual input to activities, which were also the ones most highly valued by staff.

\section{Box 3. Not just money: time and ideas too}

According to an independent evaluation, many RECOFTC staff perceived the partnership as a relationship of donor and recipient. On the SNV side too, some staff felt there was an imbalance in the type and level of resources contributed by each partner - as one commented: 'a partnership should be more than one sponsoring the other' (cited in Nass 2007: 10). While the funding from SNV was critical to the agreed work programme, it also brought an imbalance to the relationship, with activities being led by RECOFTC, who then reported to SNV on expenditure and progress.

This imbalance did not apply to all the activities under the partnership, however. In some key activities (a learning initiative on benefit sharing in CBNRM, the development of a training course on natural-resource governance, and a practitioner-oriented publication on NTFP enterprises), a more balanced contribution of money, time, and ideas was achieved. These helped to demonstrate the value of the partnership to the staff involved, contributed to trust and good communication between staff in the two organisations, and were also the activities perceived by staff to have the greatest impact.

Box 3 highlights the fact that partnerships run on more than money. Where staff commit their time and ideas to activities, the activities gain a certain momentum and dynamic which attract 
other actors to invest in them. The evaluation concluded that it may in fact be preferable to have fewer but even financial resources allocated to activities by the partners, which become a basis for mobilising additional resources from other sources, as happened in the examples of alliances discussed earlier (Nass 2007). The importance of tracking time alongside money is another lesson that emerged, to better reflect the range of resources that organisations might commit to partnership activities (Table 1, 2d and 2f).

A further factor in the commitment of staff time was that the management of the partnership and related activities fell ultimately to only a few members of staff. As one co-ordinator noted, 'Every day this partnership needs some of my attention' (cited in Nass 2007: 8). Furthermore, although a large number of discrete activities were planned under the partnership, the implementation, particularly on the RECOFTC side, was focused on two key programmes and a small handful of individuals within them. However, the time invested in partnership maintenance was not a recognised aspect of individual work plans. This meant that at times the partnership was a lower priority than other competing commitments, leading to comments such as: "In future SNV must put in a bit more time, but RECOFTC can also invest a bit more, they seem very rushed in their work lately' (cited in Nass 2007: 11). This situation might have been alleviated if there had been greater organisational recognition of the time involved in partnership maintenance and implementation and the tracking of this, as well as consolidation of disparate activities in planning processes (Table 1, 2e and 2f). In SNV, for example, the partnership co-ordinator had substantially more time allocated to partnership management in his work programme during the second year, which enabled SNV to extend involvement in joint activities.

Table 3 summarises positive and negative aspects of the functioning of the partnership.

Table 3: Strengths and weaknesses in partnership functioning

\begin{tabular}{|c|c|}
\hline Strengths & Weaknesses \\
\hline \multicolumn{2}{|l|}{$\begin{array}{l}\text { High level of trust between staff (nurtured } \\
\text { through open and informal communication, } \\
\text { close collaboration on activities) }\end{array}$} \\
\hline \multicolumn{2}{|l|}{$\begin{array}{l}\text { Mutual trust at the organisational level, } \\
\text { based on reputation and knowledge of each } \\
\text { other's work }\end{array}$} \\
\hline $\begin{array}{l}\text { Where joint intellectual investment } \\
\text { occurred, it was highly valued and seen as } \\
\text { innovative and effective }\end{array}$ & $\begin{array}{l}\text { Imbalance in type and level of resources contributed by } \\
\text { partners led to one-way accountability and perception of } \\
\text { a donor-recipient relationship }\end{array}$ \\
\hline Flexibility to adapt work programme & $\begin{array}{l}\text { Some 'mushrooming' of activities, which could have } \\
\text { been checked if clearer objectives and outcomes had } \\
\text { been articulated for the partnership }\end{array}$ \\
\hline \multicolumn{2}{|l|}{$\begin{array}{l}\text { Mobilisation of additional resources for } \\
\text { some activities }\end{array}$} \\
\hline & $\begin{array}{l}\text { Time taken in maintaining the partnership was invested } \\
\text { by a few staff, but the amount of time needed was not } \\
\text { fully recognised in their work programme }\end{array}$ \\
\hline & $\begin{array}{l}\text { Expenditure was tracked, but not staff time inputs. A } \\
\text { simple system for tracking staff time could help staff to } \\
\text { understand the type and extent of inputs to partnership } \\
\text { activities by each organisation and support discussion of } \\
\text { perceived issues with this. }\end{array}$ \\
\hline
\end{tabular}




\section{Partnership outcomes}

The emphasis in evaluation of this partnership to date has been on outputs and outcomes (summarised in Table 4) rather than impacts at the beneficiary level. The latter was not prioritised at this early stage of the partnership. With this limitation in mind, some notable outcomes and outputs were observed in the independent partnership evaluation (Table 1, 3a):

- The second Community Forestry Forum supported through the partnership (a high-level meeting of regional policy makers) and related publications contributed to raising the profile of Community Forestry and related policy issues (RECOFTC 2007), particularly in countries such as Bhutan and Vietnam (Table 1, 3c and 3d).

- The development of governance training for local government officials, a joint activity over the two years of the partnership, was undertaken through close collaboration between SNV and RECOFTC staff, with the support of a consultant (former SNV staff). The pilot training event highlighted many important lessons for future development of the material and the strong demand for capacity development in this area among clients of both organisations (Table 1, 3b and 3d).

- A learning initiative on benefit and cost sharing in community-based NRM, initially developed by WWF and RECOFTC, drew additional funding and SNV resource persons through the partnership. A series of national-level workshops of government and civil-society organisations (CSOs) was arranged, with RECOFTC support, by WWF in Cambodia, Lao PDR, and Vietnam. SNV staff actively contributed to the workshops in Lao PDR and Vietnam. The national workshops fed into a regional workshop, and the cross-cutting lessons were compiled into a book (Mahanty et al. 2007) and a policy brief (RECOFTC 2007), and were presented at the Second Community Forestry Forum. A later extension of this activity involved a study by a leading organisation in Nepal on pro-poor approaches and benefitsharing in community-based forest management, which is being developed into a practitioner toolkit (Table 1, 3c).

The partnership also supported a number of regional conferences and workshops, but there was little investment in follow-up activities. In particular, the partnership evaluation noted a gap in follow-up on the areas for further work identified at many of these events. As discussed earlier, the annual funding timeframe for partnership activities tended to foster a focus on short-term activities such as publications and events, rather than on-going programmes. To build on and capitalise on partnership activities, a longer-term approach to the partnership is needed, reflected in budgets and planning horizons. This is perhaps true for most development initiatives, but particularly so in NRM. The partnership could achieve initial ripples in new thinking and capacity fairly quickly, but it takes longer to achieve a wider uptake of new knowledge and its translation to action through strengthened regional capacity.

For the two organisations involved in the partnership, the collaboration also facilitated access to networks and initiatives that might not have developed otherwise. In the case of SNV, the relationship with RECOFTC enabled the organisation to link with and gain a profile in regional forums. For RECOFTC, SNV's field presence enabled access to field-based experiences and local partners that enhanced their national-level presence and recognition (partnership outcome 2).

Adding value to each other's programmes, creating synergies, and multiplier effects are important reasons for having partnerships in the first place, and the examples provided earlier illustrate that this was occurring in the SNV-RECOFTC case. These synergies were facilitated at a number of levels. Partnership activities often built on or extended activities that either organisation was already planning for, and the partnership funding enabled additional 
components to be added (such as publications) or enrichment of activities (for example through the provision of resource persons to a workshop). The partnership reduced competitiveness between organisations, while fostering collaboration on activities of mutual interest.

As noted earlier, there were also many cases where partnership funds were used to leverage or build on resources from other organisations, such as WWF Greater Mekong Program, FAO, ICRAF, ITTO, DGIS and others. Having a core group of organisations involved with an activity made it easier to gain the commitment of others to an initiative. One question that emerged in relation to this alliance building was whether it would have been appropriate to add other organisations to the formal partnership. The general sense was that it was good to have the flexibility to engage with a range of other organisations when strategically useful. Adding partners to the formal partnership would have added to the complexity and costs involved in maintaining it, so it was not seen as useful approach.

An issue with synergies and multipliers is that they are difficult to monitor. Where partnership activities built on existing organisational initiatives, the impacts were difficult to disentangle. For example, the partnership activities undertaken by the Regional Analysis and Representation programme within RECOFTC may have been implemented without the partnership, but the SNV involvement added value in the form of expertise and resources. The issue of attribution becomes complex, because capturing information on such additional impacts is not straightforward (Marra 2004). This perhaps needs to be acknowledged in evaluation processes, both for the partnership and for organisational programmes. With the current emphasis on partnerships globally, it would be useful to foster further discussion on effective approaches to monitoring partnership impacts (for example, Kaftarian and Yi 2000; Table 1, 3f).

Finally, a major strength of the partnership has been a strong emphasis on learning and reflection through supporting student research on the partnership and an independent evaluation (Table 1, 3e); such external facilitation often plays an important role in highlighting sensitive issues that staff might otherwise find difficult to raise (Fowler 2007). The learning focus is due in part to the emphasis on capacity building and learning in the two organisations. This 'organisational readiness' or partnership (the intra-organisational factors flagged earlier), which can receive only brief comment here, is perhaps crucial to partnership effectiveness and worthy of further research. In the SNV-RECOFTC case, the organisations have learned from and moved through periods of perceived imbalance in their contributions to the partnership, as well as an over-ambitious work programme to adapt their processes and programmes for greater effectiveness, reflected in the new partnership agreement signed in 2008.

Table 4: Strengths and weaknesses in partnership outcomes

\begin{tabular}{|c|c|}
\hline Strengths & Weaknesses \\
\hline $\begin{array}{l}\text { Many examples of partnership supported activities } \\
\text { with useful outcomes for clients and stakeholders. }\end{array}$ & Focus on outputs and outcomes rather than impact. \\
\hline $\begin{array}{l}\text { Many examples of synergistic and multiplier } \\
\text { effects, leveraging of funds, and collaboration } \\
\text { with other organisations. }\end{array}$ & $\begin{array}{l}\text { Difficult to monitor partnership impacts when they } \\
\text { add to or enhance activities that might have } \\
\text { proceeded in some form without the partnership. }\end{array}$ \\
\hline \multicolumn{2}{|l|}{$\begin{array}{l}\text { Each organisation benefited in terms of their } \\
\text { respective linkages and agendas. }\end{array}$} \\
\hline $\begin{array}{l}\text { Useful areas for follow-up were identified through } \\
\text { a number of partnership-supported activities. }\end{array}$ & $\begin{array}{l}\text { Short-term funding and planning horizons } \\
\text { contributed to mushrooming of smaller activities, } \\
\text { rather than following up and building on activities. }\end{array}$ \\
\hline Emphasis on adaptive learning. & \\
\hline
\end{tabular}




\section{Conclusions: implications for inter-organisational partnerships}

The SNV-RECOFTC experience demonstrates that partnerships can effectively strengthen the resources, networks, knowledge, and outcomes of partner organisations. Commitment to learning within the partnership enables it to develop and strengthen over time. The second three-year phase of the partnership differs from the first in some important ways: equal intellectual contribution, a focus on joint resource mobilisation, streamlining activities to a few key thematic areas (value-chain development of forest products, governance and forestry, and reduced emissions from ecosystem degradation and deforestation), and improved partnership reporting and co-ordination.

From this process of critical reflection on the SNV-RECOFTC partnership, a number of useful lessons have emerged for other inter-organisational partnerships:

- Informal networks and communication between staff are as important as formal agreements, and both are needed for effective partnerships.

- A balance between the quick results generated through small, dispersed activities and a focused programme of work may be supported by clear analysis of useful collaborative focal points at the outset, with the flexibility to elaborate and adapt activities related to these.

- Clearly linking partnership activities with organisational priorities helps to facilitate followup and commitment, and to maximise synergies and multiplier effects.

- Relationships between organisations are ultimately founded on the 'nested partnerships' between individuals, and the trust and communication fostered within them. Conversely, the risk posed by rapid staff turnover needs to be managed by broadening the base of engagement between organisations.

- Mutuality can be undermined if organisations commit different levels and types of resource to a partnership, particularly in the absence of mechanisms to track contributions beyond funding.

- Intellectual inputs are as (or more) important than funding to underpin partnership activities.

- Partnership maintenance takes time in its own right and needs to be recognised and planned for in staff work plans.

- Flexibility and openness help to capitalise on opportunities, but need to occur in the context of clear strategic direction.

- The planning and implementation timeframe for partnerships should be longer than one year, maybe three to five years, to enable staff to build a commitment to the partnership, and to enable longer-term activities to be initiated, funded, and implemented, which is particularly important in the NRM sector.

- Partnerships can be 'open marriages', collaborating with other organisations to mobilise additional resources to extend and strengthen outcomes. For evolving and multi-programme partnerships like the SNV-RECOFTC case, this need not involve formally adding those organisations to the partnership, which would merely add complexity.

The analytical framework for partnerships developed by Brinkerhoff (2002) has proved relevant to the SNV-RECOFTC case, a partnership between two international organisations of relatively equal standing (Brinkerhoff and Brinkerhoff 2004), which nevertheless went through some imbalances and issues in working in the NRM context. A number of additional points have emerged from the SNV-RECOFTC case which might usefully be incorporated in the framework. First, financial inputs are often easier to track than intellectual and staff-time inputs, but contributing time is as significant as contributing money to the partner organisations, since this is time away from other organisational objectives and programmes. Workable systems need to be developed to account for this, as a basis for tracking resource commitments 
to partnerships. Second, the planning horizons for partnerships with a capacity-building focus need to be long enough to enable uptake of new knowledge and development of capacity certainly more than one or two years. This aspect is particularly important in NRM, which requires co-ordination across diverse actors and scales.

Finally, the SNV-RECOFTC experience demonstrates that a commitment to critical reflection, learning, adapting, and sharing lessons is a crucial foundation for the on-going development of partnerships. SNV and RECOFTC were able to address the lessons from the first phase of the partnership in their second agreement, which runs for three years. To achieve this, it has been important to subject the partnership to independent review, including research and independent evaluation, which helped busy staff members to stop and reflect on lessons and areas for future development and change. Such assessment and reflection processes would also benefit from the development of appropriate frameworks and indicators for monitoring specific partnership impacts, particularly where they build on or add to other organisational activities.

\section{References}

Brinkerhoff, J. M. (2002) 'Assessing and improving partnership relationships and outcomes: a proposed framework', Evaluation and Program Planning 25: 215-31.

Brinkerhoff, D. W. and J. M. Brinkerhoff (2004) 'Partnerships between international donors and non-governmental development organizations: opportunities and constraints', International Review of Administrative Sciences 70: 253-69.

Donnelly, P. (2007) 'Developing a Strategy and Guidelines for Working in Partnerships: Exploring the Basis, Process and Outcome of (Non-corporate) Relationships in which RECOFTC Engages or Would Like to Engage', unpublished report to RECOFTC, Bangkok: RECOFTC.

Fowler, A. F. (1998) 'Authentic NGDO partnerships in the New Policy Agenda for international aid: dead end or light ahead?', Development and Change 29: 137-59.

Fowler, A. F. (2007) 'Getting to partnership: the neglected role of facilitation', Capacity.org 31, http:// capacity.org/en/journal/guest_column/getting_to_partnership.

Hoksbergen, R. (2005) 'Building civil society through partnership: lessons from a case study of the Christian Reformed World Relief Committee', Development in Practice 15 (1): 16-27.

Kaftarian, S. J. and P. Yi (2000) 'Breaking new frontiers: outcome evaluations of community-based program', Evaluation and Program Planning 23: 337-9.

Lister, S. (2000) 'Power in partnership? An analysis of an NGO's relationships with its partners', Journal of International Development 12: 227-39.

Mahanty, S., K. Burslem, and E. Lee (eds.) (2007) A Fair Share? Experiences in Benefit Sharing from Community Managed Resources in Asia, Bangkok: RECOFTC, WWF and SNV.

Marra, M. (2004) 'Knowledge partnerships for development: what challenges for evaluation?', Evaluation and Program Planning 27: 151-60.

Nass, L. (2007) 'Evaluation Report: RECOFTC - SNV Asia Partnership 2005-2007', Report to RECOFTC and SNV, Honoi: SNV and RECOFTC.

Pickard, M. (2007) 'Reflections on relationships: the nature of partnership according to five NGOs in southern Mexico', Development in Practice 17 (4\&5): 575-81.

Regional Community Forestry Training Center for Asia and the Pacific (2007) Sharing the Wealth: Policy and Legal Frameworks to Support Equitable Sharing of the Costs and Benefits from Community Forestry, Bangkok: RECOFTC, FAO and SNV.

Tonkiss, F. and A. Passey (1999) 'Trust, confidence and voluntary organisations: between values and institutions', Sociology 33: 257-74.

Vincent, R. and A. Byrne (2006) 'Enhancing learning in development partnerships', Development in Practice 16: 385-99.

Ylitalo, J., K. Ziegler, and E. Mäki (2005) 'Learning How to Collaborate in a Long-term Interorganizational Relationship', Proceedings of the 5th International Conference on Knowledge, Culture and Change in Organisations, Rhodes, 19-22 July. 


\section{The authors}

Sango Mahanty (corresponding author) has extensive experience in participatory natural-resource management in the Asia-Pacific region, particularly on livelihoods, governance, and social learning. She worked with RECOFTC from 2005 to 2007 and in her second year co-ordinated the SNVRECOFTC partnership. She is a Research and Teaching Fellow in Resource Management in the Asia Pacific Program at the Australian National University. Contact details: Resource Management in the Asia Pacific Program, Research School of Pacific and Asian Studies, ANU College of Asia and the Pacific, Australian National University, Canberra ACT 0200, Australia. < sango.mahanty@anu.edu.au>

Yurdi Yasmi has worked on issues related to forest and nature governance in Asia for ten years. His research mainly focuses on sustainable forest management, community participation, decentralisation, and conflict management. Currently he is a Program Officer at RECOFTC and responsible for co-ordinating the SNV-RECOFTC partnership.

John Guernier has wide experience in community-based natural-resource management in Asia, Africa, Latin America, and Australia. He currently manages the Regional Analysis and Representation Program at RECOFTC. In addition to supporting the RECOFTC-SNV partnership, he manages RECOFTC's relationships with several other international and national organisations.

Rob Ukkerman has worked in development programmes in Africa, Latin America, and Asia since 1985, starting in agriculture and moving on to natural-resource management and environmental planning. He has been regional network leader for SNV's forestry programme in Asia and SNV co-ordinator for the SNV RECOFTC partnership since 2007.

Lucia Nass has wide experience in rural social development, with a focus on capacity strengthening of NGOs and local governments. She has facilitated strategic change in national and international development organisations and training institutions. She evaluated the SNV-RECOFTC partnership as an independent consultant and is currently based in Vietnam as Regional Governance Adviser for SNV in Asia. 